\title{
Long term outcome and cost-effectiveness of stenting versus balloon angioplasty for acute myocardial infarction
}

H Suryapranata, J P Ottervanger, E Nibbering, A W J van’t Hof, J C A Hoorntje, M J de Boer, M J Al, F Zijlstra

\begin{abstract}
Objective-To investigate the long term clinical outcome and cost-effectiveness of stenting compared with balloon angioplasty in patients with acute myocardial infarction.

Methods-Patients with acute myocardial infarction were randomly allocated to primary stenting (112) or balloon angioplasty (115). The primary end point was the cumulative first event rate of death, non-fatal reinfarction, or target vessel revascularisation. Secondary end points were restenosis at six months and the cost-effectiveness at follow up.

Results-After 24 months, the combined clinical end point of death/reinfarction was $4 \%$ after stenting and $11 \%$ after balloon angioplasty $(p=0.04)$. Subsequent target vessel revascularisation was necessary in 15 patients (13\%) after stenting and in $39(34 \%)$ after balloon angioplasty $(\mathrm{p}<0.001)$. The cumulative cardiac event-free survival rate was also higher after stenting $(84 \%$ v $62 \%, \mathrm{p}<0.001)$. The angiographic restenosis rate after stenting was less than after balloon angioplasty $(12 \% v 34 \%, \mathrm{p}<0.001)$. Despite the higher initial costs of stenting (Dfl $21484 v$ Dfl $18625, \mathrm{p}<0.001$ ), the cumulative costs at 24 months were comparable with those of balloon angioplasty (Dfl $31423 v$ Dfl 32 933, $\mathrm{p}=0.83$ ).

Conclusions-Compared with balloon angioplasty, primary stenting for acute myocardial infarction results in a better long term clinical outcome without increased cost.

(Heart 2001;85:667-671)
\end{abstract}

Keywords: stenting; angioplasty; myocardial infarction; cost-benefit analysis

The most important goal of the initial treatment of acute myocardial infarction is early and complete reperfusion of the infarct related coronary artery. Compared with thrombolytic treatment, primary angioplasty for acute myocardial infarction causes a decrease in recurrent infarction and death after both short term ${ }^{1}$ and long term follow up. ${ }^{2}$ These beneficial effects are mainly produced by a higher patency rate of the infarct related vessel after primary angioplasty. ${ }^{3}$ However, recurrent ischaemia, early reocclusion of the infarct related vessel, and late restenosis requiring subsequent target vessel revascularisation remain potential clinical problems after primary angioplasty.

There have been several randomised trials showing that the use of stents in primary angioplasty results in a better event-free survival than after primary angioplasty with balloon alone. ${ }^{4-9}$ In particular, the need for repeat target vessel revascularisation during follow up is less after the use of stents.

Angioplasty with the use of stents is more expensive than angioplasty with balloon alone, so there may be concerns that the high initial cost of stenting is a major limitation of this approach. ${ }^{10-12}$ However, as patients with stents have fewer readmissions and revascularisation procedures during follow up, the long term costs may be comparable. Because long term clinical outcome and cost-effectiveness of stents in primary angioplasty have not been reported, we examined these variables in patients involved in our prospective randomised trial of stents versus balloon angioplasty for acute myocardial infarction. ${ }^{9}$

\section{Methods}

The study protocol has been described previously. ${ }^{9}$ In brief, 227 patients with acute myocardial infarction presenting within six hours, and in whom the infarct related vessel was considered suitable for stenting, were randomised to primary stenting or balloon angioplasty. During the study period, a further 225 patients $(50 \%)$ were excluded, mainly because of small and diffusely diseased infarct related vessels. $^{3}$

Bare Palmaz-Schatz stents were hand mounted on the balloon used for predilatation. If necessary, high pressure inflation was performed with a bigger sized balloon. Angiographic success, subacute occlusion, and bail out stenting were defined as previously described. ${ }^{913}$ Quantitative coronary angiography of the target lesion was performed in all patients enrolled into the study on site, as well as by an independent core laboratory (Cardialysis, Rotterdam, Netherlands), blinded to all clinical data and outcome. The degree of stenosis (per cent) was assessed in the angiographic view in which the stenosis appeared most severe immediately before and after angioplasty, and at follow up angiography. Thrombolytic treatment, platelet glycoprotein IIb/IIIa receptor antagonists, and intravascular ultrasound were not used. Radionuclide ejection fraction was assessed at discharge and at six months. ${ }^{2}$ 
Table 1 Baseline characteristics and in-hospital outcome of the 227 randomised patients

\begin{tabular}{lll}
\hline & \multicolumn{2}{l}{ Treatment groups } \\
\cline { 2 - 3 } Characteristic & Stent $(n=112)$ & Balloon $(n=115)$ \\
\hline Age (years) & $59(11)$ & $57(11)$ \\
Male & $93(83 \%)$ & $98(85 \%)$ \\
Previous infarction & $15(13 \%)$ & $15(13 \%)$ \\
Killip class $\geqslant 2$ at admission & $25(22 \%)$ & $20(17 \%)$ \\
Symptom onset to admission (min) & $217(222)$ & $211(242)$ \\
Admission to first inflation (min) & $62(82)$ & $62(63)$ \\
Symptom onset to admission $<3 \mathrm{~h}$ & $75(67 \%)$ & $79(69 \%)$ \\
Multivessel disease & $49(44 \%)$ & $51(44 \%)$ \\
Infarct artery: & & \\
$\quad$ Left anterior descending & $66(59 \%)$ & $70(61 \%)$ \\
$\quad$ Right coronary & $34(30 \%)$ & $35(30 \%)$ \\
Circumflex & $12(11 \%)$ & $10(9 \%)$ \\
Initially occluded infarct artery & $97(87 \%)$ & $96(83 \%)$ \\
Angiographic success & $110(98 \%)$ & $110(96 \%)$ \\
Subacute occlusion & $1(1 \%)$ & $5(4 \%)$ \\
Crossover (bail out) & $2(2 \%)$ & $15(13 \%)^{\star}$ \\
Intra-aortic balloon pumping & $18(16 \%)$ & $15(13 \%)$ \\
Major bleeding complications & $7(6 \%)$ & $3(3 \%)$ \\
Death & $2(2 \%)$ & $3(3 \%)$ \\
Reinfarction & $1(1 \%)$ & $5(4 \%)$ \\
\hline
\end{tabular}

Values are mean (SD) or $\mathrm{n}(\%)$.

${ }^{\star} \mathrm{p}<0.002$.

Table 2 Cumulative clinical outcome at 24 months

\begin{tabular}{llll}
\hline & $\begin{array}{l}\text { Stent } \\
(n=112)\end{array}$ & $\begin{array}{l}\text { Balloon } \\
(n=115)\end{array}$ & $p$ Value \\
\hline Death & $3(3 \%)$ & $4(3 \%)$ & 1.00 \\
Reinfarction & $1(1 \%)$ & $10(9 \%)$ & 0.01 \\
Death/reinfarction & $4(4 \%)$ & $13(11 \%)$ & 0.04 \\
Target vessel revascularisation & $15(13 \%)$ & $39(34 \%)$ & 0.0003 \\
$\quad$ Subsequent bypass surgery & $7(6 \%)$ & $18(16 \%)$ & 0.033 \\
$\quad$ Repeat angioplasty & $8(7 \%)$ & $21(18 \%)$ & 0.016 \\
Cumulative cardiac event-free survivor & $94(84 \%)$ & $71(62 \%)$ & 0.0002 \\
\hline
\end{tabular}

Values are $\mathrm{n}(\%)$.

The primary study end point was the cumulative first event rate of death, non-fatal reinfarction, or the need for myocardial revascularisation of the target vessel at follow up, as previously defined. ${ }^{9}$ Myocardial infarction was defined as electrocardiographic signs of infarction combined with an increase in serum creatine kinase $(\mathrm{CK})>200 \mathrm{U} / 1$ and creatine kinase $\mathrm{MB}$ isoenzyme fraction/total creatine $\geqslant 10 \%$.
Revascularisation was defined as angioplasty or bypass surgery performed because of restenosis of the target lesion. The indication for revascularisation had to be substantiated by symptoms and ECG or scintigraphic evidence of ischaemia at rest or during exercise. Subsequent revascularisation involving other vessels did not constitute an end point. Two cardiologists blinded to treatment assignments reviewed all events.

The secondary study end points consisted of angiographic restenosis at six months and cost-effectiveness at follow up. Angiographic restenosis was defined as at least $50 \%$ diameter stenosis of the target lesion on a follow up angiogram. ${ }^{913}$ Follow up assessment of resource use and health status was made through telephone interviews with the general practitioner of each patient and was conducted 24 months after the procedure. Patient reported clinical events and resource use during follow up were confirmed from hospital discharge summaries. The calculation of costs was based on the direct medical costs, including all aspects of medical care. ${ }^{14}{ }^{15}$ These include resources use during the initial procedure, all hospital admissions (coronary care unit, intensive care unit, general ward), and other diagnostic or therapeutic proceduresincluding repeat angiography-during follow up. Follow up resource use was limited to cardiac hospital admissions and cardiac outpatient visits and diagnostic tests. Cardiac hospital admissions included those for any type of chest pain, congestive heart failure, arrhythmia, or any other cardiovascular diagnosis.

Costs per patient were calculated as the product of each patient's use of resources and the corresponding unit cost. All costs are given in Dutch guilders (Dfl). The balance between costs and effects was addressed by calculation of the incremental cost-effectiveness ratio (the

Table 3 Cumulative costs per patient in Dutch guilders (Dfl) during 24 months follow up

\begin{tabular}{|c|c|c|c|c|c|c|}
\hline & \multicolumn{2}{|c|}{ Resource utilisation } & \multirow[b]{2}{*}{ Unit cost $(D f l)$} & \multicolumn{2}{|c|}{ Average cost/patient } & \multirow[b]{2}{*}{$p$ Value } \\
\hline & $\begin{array}{l}\text { Stent } \\
(n=112)\end{array}$ & $\begin{array}{l}\text { Balloon } \\
(n=115)\end{array}$ & & $\begin{array}{l}\text { Stent } \\
(n=112)\end{array}$ & $\begin{array}{l}\text { Balloon } \\
(n=115)\end{array}$ & \\
\hline \multicolumn{7}{|l|}{ In hospital costs } \\
\hline PTCA procedure & 1 & 1 & 8535 & 8535 & 8535 & 1 \\
\hline Stent & 1.17 & 0.24 & 2200 & 2573 & 535 & 0.0001 \\
\hline IABP & 0.16 & 0.13 & 1300 & 221 & 170 & 0.5 \\
\hline Angiography & 0.02 & 0.03 & 3882 & 69 & 135 & 0.43 \\
\hline $\mathrm{CABG}$ & 0.02 & 0.01 & 26052 & 465 & 227 & 0.55 \\
\hline Repeat PTCA & 0.01 & 0.04 & 8535 & 76 & 371 & 0.11 \\
\hline CCU (days) & 2.42 & 2.2 & 2200 & 5323 & 4840 & 0.82 \\
\hline Ward (days) & 5.28 & 4.77 & 800 & 4221 & 3812 & 0.18 \\
\hline Total cost & & & & 21484 & 18625 & 0.0001 \\
\hline \multicolumn{7}{|l|}{ Follow up costs } \\
\hline Angiography & 0.88 & 0.85 & 3882 & 3397 & 3308 & 0.53 \\
\hline $\mathrm{CABG}$ & 0.04 & 0.14 & 26052 & 930 & 3624 & 0.006 \\
\hline Repeat PTCA & 0.10 & 0.14 & 8535 & 836 & 1187 & 0.15 \\
\hline Stent & 0.03 & 0.12 & 2200 & 59 & 268 & 0.012 \\
\hline IABP & 0.01 & 0 & 1300 & 12 & 0 & 0.31 \\
\hline CCU (days) & 0.29 & 0.59 & 2200 & 648 & 1301 & 0.018 \\
\hline Ward (days) & 3.94 & 4.62 & 800 & 3150 & 3694 & 0.34 \\
\hline Follow up visits & 4.10 & 3.91 & 125 & 512 & 489 & 0.58 \\
\hline Echo & 0.19 & 0.22 & 128 & 24 & 28 & 0.29 \\
\hline Stress test & 0.71 & 0.84 & 115 & 81 & 97 & 0.26 \\
\hline $\mathrm{EF}$ & 0.88 & 0.96 & 325 & 287 & 311 & 0.56 \\
\hline Total cost & & & & 9939 & 14308 & 0.028 \\
\hline Total cost per patient & & & & 31423 & 32933 & 0.83 \\
\hline
\end{tabular}

CABG, bypass surgery; CCU, coronary or intensive care; echo, echocardiography; EF, radionuclide ejection fraction; IABP, intraaortic balloon pumping; PTCA, percutaneous transluminal coronary angioplasty. 

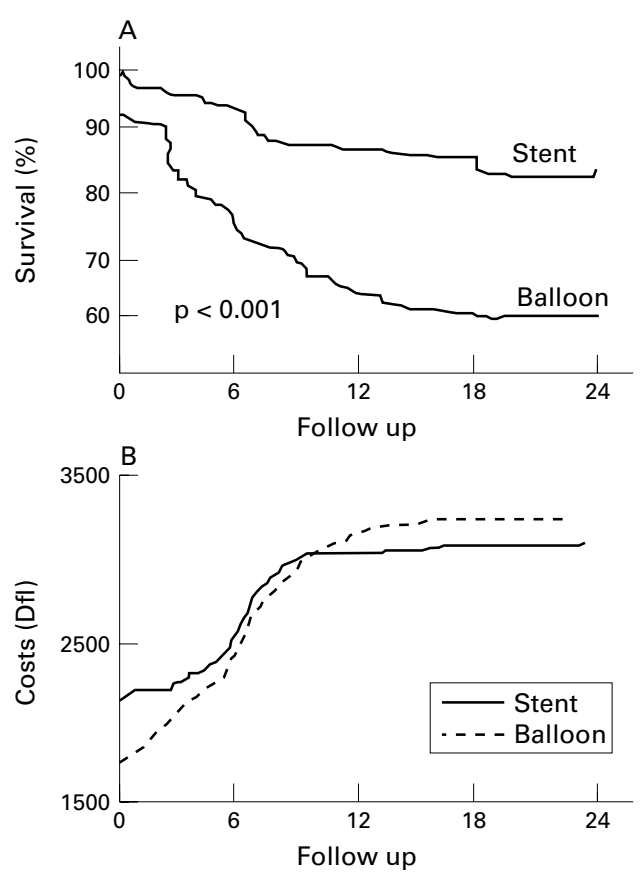

Figure 1 (A) Cumulative first event-free survival (no death, non-fatal reinfarction, or myocardial

revascularisation during 24 months of follow up).

(B) Cumulative costs per patient in Dutch guilders ( $D f l)$ during follow up in both stent (solid line) and balloon (dotted line) groups.

average cost per patient in the stent group minus that in the balloon group divided by the percentage reduction in event-free survival) and the average cost-effectiveness ratios for both groups (the average costs per patient divided by the percentage of event-free survivors). No patient was lost to follow up.

DATA ANALYSIS

Sample size calculations have been described. ${ }^{9}$ Data were analysed according to the intention to treat principle. Continuous variables are expressed as means (SD) and were compared using the Student $t$ test. The $\chi^{2}$ test was used to compare proportions, or a Fisher's exact test when appropriate. Event-free survival was assessed by Kaplan-Meier method, using the

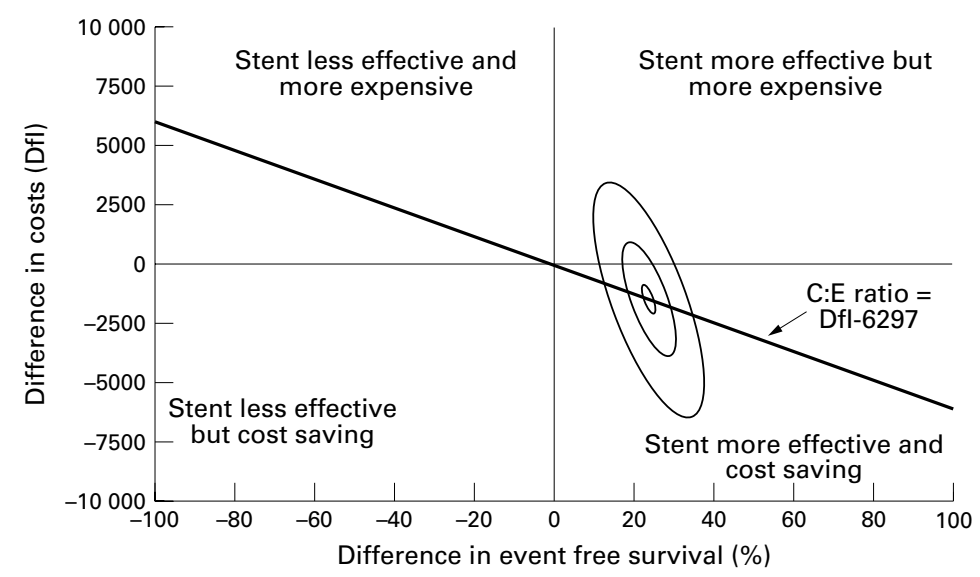

Figure 2 A bivariate normal distribution of differences in costs and effects in a two dimensional plane, together with the uncertainties surrounding the estimates. A 95\% confidence ellipse, a simultaneous confidence region for both costs and effects, is depicted. The probability that the inner ellipse includes the true incremental costs and effectiveness is $5 \%$. For the middle ellipse, this is 50\%, and for the outer ellipse, $95 \%$. $\log$ rank test. Differences in costs were tested parametrically ( $t$ test) and non-parametrically (Mann-Whitney U test). Costs and effects are expressed in a two dimensional plane, and the uncertainties surrounding the estimates are expressed by confidence ellipses, ${ }^{15}$ assuming that the average costs and effectiveness approached a bivariate normal distribution. Relations were assessed using Pearson's correlation coefficient. A two sided probability value of $\mathrm{p}<0.05$ was considered significant.

\section{Results}

In all, 227 patients were included in the study, of whom 112 were randomised to primary stenting and 115 to balloon angioplasty. The baseline characteristics and in hospital outcome are listed in table 1 . There were no differences in the baseline characteristics between the two groups. In two patients (2\%) allocated to stenting, the target lesion could not be crossed by the stent owing to proximal vessel tortuosity, but the result was excellent after balloon angioplasty. Bail out stenting was needed in 15 patients (13\%) allocated to balloon angioplasty, as a result of major dissection with threatening vessel occlusion.

Tables 2 and 3 show the clinical outcome and the total costs during follow up. After a follow up period of 24 months the occurrence of reinfarction and the combination of death or non-fatal reinfarction was lower in patients treated with primary stenting. In fig 1 , the event-free survival curves and the cumulative costs during follow up are depicted. Despite the higher initial costs of stenting on admission, the cumulative costs after 24 months were similar between the groups. The efficiency of both treatment modes can be assessed from the average costs per event-free survivor. The average cost-effectiveness ratio (calculated from the average total costs and the event-free survival) was Dfl 37408 in the stent group and Dfl 53117 in the balloon group $(\mathrm{p}<0.001)$. The incremental cost-effectiveness ratio was estimated at Dfl -6297 (95\% confidence interval Dfl -18828 to Dfl 16 390). The uncertainties of this estimate are indicated in fig 2 , where both differences in costs and effects are depicted as a bivariate normal distribution in a two dimensional plane.

Follow up angiography was obtained in 197 patients $(87 \%)$. Five patients died (three after stenting and two after balloon angioplasty), and eight underwent bypass surgery before scheduled angiography (one after stenting and seven after balloon angioplasty); seven patients in the stent group and 10 in the balloon group refused angiography. Matched quantitative analyses, obtained from the independent core laboratory, are shown in table 4 and fig 3, which were comparable to those analysed on site. Matched ejection fractions, obtained before discharge and at six months, increased significantly in both groups, from (mean (SD)) $43.4(10.5) \%$ to $45.8(11.0) \% \quad(p=0.023)$ after stenting, and from $45.0(10.7)$ to 46.1 $(11.6) \%(p=0.019)$ after balloon angioplasty. 
Table 4 Core laboratory quantitative angiographic results

\begin{tabular}{llll}
\hline Matched analysis & Stent $(n=101)$ & Balloon $(n=96)$ & $p$ Value \\
\hline Time to follow up (months) & $6.90(2.36)$ & $6.32(2.32)$ & 0.084 \\
Minimum lumen diameter (mm) & & & \\
$\quad$ Pre & $0.24(0.46)$ & $0.33(0.51)$ & 0.20 \\
$\quad$ Post & $2.56(0.38)^{\star}$ & $2.17(0.48)^{\star}$ & $<0.0001$ \\
$\quad$ Follow up & $2.04(0.63)^{\star}$ & $1.64(0.83)^{\star}$ & 0.0002 \\
Diameter stenosis (\%) & & & \\
$\quad$ Pre & $91.5(15.4)$ & $89.1(16.7)$ & 0.28 \\
$\quad$ Post & $18.0(6.5)^{\star}$ & $29.1(9.2)^{\star}$ & $<0.0001$ \\
$\quad$ Follow up & $33.4(18.8)^{\star}$ & $47.3(23.6)^{\star}$ & $<0.0001$ \\
Reference diameter (mm) & & & \\
$\quad$ Post & $3.15(0.47)$ & $3.11(0.55)$ & 0.25 \\
$\quad$ Follow up & $3.08(0.44)$ & $3.09(0.56)$ & 0.68 \\
Restenosis (diameter stenosis $>50 \%)$ & $12(11.9 \%)$ & $33(34.4 \%)$ & 0.0002 \\
\hline
\end{tabular}

Values are means $(\mathrm{SD})$ or $\mathrm{n}(\%)$.

${ }^{\star} \mathrm{p}<0.0001$ versus pre and/or post procedure.

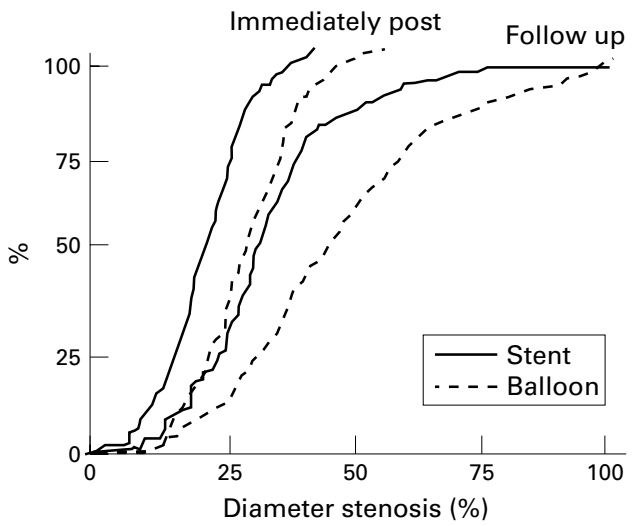

Figure 3 Cumulative frequency of diameter stenosis (\%) in both groups, as obtained from the independent core laboratory.

\section{Discussion}

This is the first randomised trial to report the cost-effectiveness and long term clinical and angiographic outcome of primary stenting for acute myocardial infarction. Primary stenting results in a better long term clinical outcome and is more cost-effective than conventional balloon angioplasty in selected patients with acute myocardial infarction. Our results also confirm the long term safety and efficacy of stenting without ultrasound guidance and without conventional anticoagulant treatment. ${ }^{16}$ Thus the major advantage of primary stenting in this setting is that these patients can be managed more efficiently and more definitively during the acute stage of myocardial infarction, as the combined clinical end point of death or recurrent myocardial infarction and the need for subsequent reintervention are significantly reduced when compared with balloon angioplasty.

The overall mortality (3\%) and recurrent myocardial infarction rates $(4 \%)$ at 24 months are comparable with those reported in our previous trial of thrombolysis versus primary angioplasty. $^{2}$ This favourable outcome may reflect the short time delay from admission to first inflation (62 minutes), and the fact that most patients were admitted within three hours after symptom onset (table 1). However, no difference in mortality could be observed as it would be unlikely that stenting could further reduce the extremely low mortality achieved by balloon angioplasty. The reduction in the need for target vessel revascularisation after stenting is mainly because of a significant reduction in restenosis $(12 \%)$, which is quite favourable when compared with elective cases. ${ }^{13}$ This favourable outcome probably reflects the fact that patients selected in this trial had a larger vessel size than in other trials. ${ }^{13}$ The restenosis rate of $34 \%$ after balloon angioplasty is quite similar to our previous trial. ${ }^{17}$ To address the potential analysis bias, quantitative angiography was analysed not only by our own but also by an independent core laboratory.

The favourable results of stenting in our study are expressed not only by the efficacy data but also by the cost-effectiveness analysis. The present data indicate that - at least in the setting of a Dutch general hospital with an existing infrastructure for primary angioplasty and stenting - the cumulative costs at 24 months after stenting are similar to those of balloon angioplasty (fig 1). The differences in the costs of the initial procedure are mainly related to the longer hospital stay after stenting and the cost of the stent itself (table 3). However, the costs of stenting procedure are relatively low in our setting, because of the use of a single balloon for predilatation, stent delivery, and post-stenting dilatation. The relatively longer hospital stay in the stent group in our study, resulting in a higher initial cost, is related to the use of anticoagulant treatment in the initial phase of our trial, before the post-stent regimen was modified. ${ }^{9}$ The use of only aspirin and ticlopidine after stenting has led to a shorter hospital stay. However, the higher in-hospital costs of stenting are compensated for by the lower costs during follow up, making primary stenting a good investment. In fact, the primary stenting strategy is more costeffective than balloon angioplasty, owing to a significantly lower incidence of target vessel revascularisation. Thus the concern that stenting would be more expensive than balloon angioplasty ${ }^{10-12}$ was not confirmed in our study. These cost-effectiveness data are comparable to more recent studies of the costs of stents in daily practice. ${ }^{18} 19$

Several limitations of this study must be considered. ${ }^{9}$ The present cost-effectiveness analysis is based on a single centre trial. Thus it might not be universally applicable to other hospitals or health care facilities. However, it can be extensively modified according to the economic standards in other European or US hospitals. Estimates can be obtained by using local unit cost estimates and the corresponding data on use of resources. As our hospital has a high volume of primary angioplasty, the clinical outcome in both treatment groups in our study may be better than in hospitals with less frequent primary angioplasty. ${ }^{20}$ The trial could not of course be blinded, and because follow up angiography was performed as an integral part of the trial, this might have affected the occurrence of reinterventions. ${ }^{21}$ However, a cardiac team consisting of both cardiologists and thoracic surgeons had to made the decision for reintervention in our setting, based on ECG or 
scintigraphic evidence of ischaemia at rest or during exercise. As patients receiving stents in our study had fewer readmissions and fewer symptoms, our current estimates of costs could have underestimated the economic benefits of stenting, as we did not include indirect costs associated with, for example, loss of employment.

Several issues remain to be addressed before primary stenting can be adopted routinely. Although the potential benefits of platelet glycoprotein IIb/IIIa receptor antagonists ${ }^{22-24}$ and the promising results of heparin coated stents ${ }^{21}$ have been reported, their definitive role in the setting of acute myocardial infarction is still uncertain. Furthermore, to define a subgroup of patients who will have most benefit from stenting and to determine whether similar results could also be obtained in smaller and diffusely diseased infarct related vessels, all patients are now randomised before angiography in our current ongoing trial.

CONCLUSIONS

Our randomised study of stents versus conventional balloon angioplasty in acute myocardial infarction showed, after a follow up period of two years, that coronary stenting leads to improved patient outcomes without increased long term costs.

1 Weaver WD, Simes RJ, Betriu A, et al. Comparison of primary coronary angioplasty and intravenous thrombolytic therapy for acute myocardial infarction: a quantitative review. FAMA 1997;278:2093-8.

2 Zijlstra F, Hoorntje JCA, de Boer MJ, et al. Long-term benefit of primary angioplasty as compared with thrombolytic therapy for acute myocardial infarction. $N$ Engl $f \mathrm{Med}$ 1999;341:1413-19.

3 Ottervanger JP, Liem A, de Boer MJ, et al. Limitation of myocardial infarct size after primary angioplasty: is a higher patency the only mechanism? Am Heart f 1999;137:116972 .

4 Grines CL, Cox DA, Stone GW, et al. Coronary angioplasty with or without stent implantation for acute myocardial infarction. Stent Primary Angioplasty in Myocardial

Infarction Study Group. N Engl f Med 1999;341:1949-56.
5 Maillard L, Hamon M, Khalife K, et al. A comparison of Maillard L, Hamon $\mathrm{M}$, Khalife $\mathrm{K}$, et al. A comparison of
systematic stenting and conventional balloon angioplasty systematic stenting and conventional balloon angioplasty
during percutaneous transluminal coronary angioplasty for during percutaneous transluminal coronary angioplasty for
acute myocardial infarction. STENTIM-2 Investigators. $\mathcal{F}$ acute myocardial infarction. STEN
Am Coll Cardiol 2000;35:1729-36.

Am Coll Cardiol 2000;35:1729-36.
6 Antoniucci D, Tontoro GM, Bolognese L, et al. A clinical trial comparing primary stenting of the infarct-related artery with optimal primary angioplasty for acute myocardial infarction: results from the Florence Randomized Elective Stenting in Acute Coronary Occlusion (FRESCO) trial. F Am Coll Cardiol 1998;31:1234-9.
7 Saito S, Hosokawa G, Tanaka S, et al. Primary stent implantation is superior to balloon angioplasty in acute myocardial infarction: final results of the primary angioplasty versus stent implantation in acute myocardial infarction (PASTA) trial. Cathet Cardiovasc Intervent 1999;48:262-8.

8 Rodriguez A, Bernardi V, Fernandez M, et al. In-hospital and late results of coronary stents versus conventional balloon angioplasty in acute myocardial infarction (GRAMI trial). Am f Cardiol 1998;81:1286-91.

9 Suryapranata H, van't Hof AWJ, Hoorntje JCA, et al. Randomized comparison of coronary stenting with balloon angioplasty in selected patients with acute myocardial infarction. Circulation 1998;97:2502-5.

10 Cohen DJ, Breall JA, Ho KKL, et al. Evaluating the potential cost-effectiveness of stenting as a treatment for symptomatic single-vessel coronary disease. Circulation 1994;89: matic single

11 Califf RM. Restenosis: the cost to society. Am Heart f 1995; 130:680-4.

12 Cohen DJ, Krumholz HM, Sukin CA, et al. In-hospital and one-year economic outcomes after coronary stenting or balloon angioplasty. Results from a randomized clinical trial. Circulation 1995;92:2480-7.

13 Serruys PW, de Jaegere P, Kiemeneij F, et al. A comparison of balloon expandable stent implantation with balloon angioplasty in patients with coronary artery disease. $N \mathrm{Engl}$ f Med 1994;331:489-95.

14 De Boer MJ, van Hout BA, Liem AL, et al. A cost-effective analysis of primary coronary angioplasty versus thrombolysis for acute myocardial infarction. Am f Cardiol 1995;76: $830-3$.

15 Van Hout B, van der Woude $\mathrm{T}$, de Jaegere $\mathrm{P}$, et al. Cost effectiveness of stent implantation versus PTCA: the Benestent experience. Semin Intervent Cardiol 1996;1:263 8.

16 Saito S, Hosokawa G, Kim K, et al. Primary stent implantation without coumadin in acute myocardial infarction. $\mathcal{F}$ Am Coll Cardiol 1996;28:74-81.

17 van't Hof AWJ, de Boer MJ, Suryapranata $H$, et al. Incidence and predictors of restenosis after successful primary coronary angioplasty for acute myocardial infarction: the importance of age and procedural result. Am Heart f 1998; 136:518-27.

18 Peterson ED, Cowper PA, DeLong ER, et al. Acute and long-term cost implications of coronary stenting. $7 \mathrm{Am}$ Coll Cardiol 1999;33:1610-18.

19 Ikeda S, Bosch J, Banz K, et al. Economic outcomes analysis of stenting versus percutaneous transluminal coronary of stenting versus percutaneous transluminal coronary
angioplasty for patients with coronary artery disease in angioplasty for patients with coronary

20 Canto JG, Every NR, Magid DJ. The volume of primary angioplasty procedures and survival after acute myocardial infarction. National registry of myocardial infarction 2 investigators. N Engl F Med 2000;342:1573-80.

21 Serruys PW, van Hout B, Bonnier H, et al. Randomised comparison of implantation of heparin-coated stents with balloon angioplasty in selected patients with coronary artery disease (Benestent II). Lancet 1998;352:673-81.

22 Neumann FJ, Blasini R, Schmitt C, et al. Effect of glycoprotein IIb/IIIa receptor blockade on recovery of coronary flow and left ventricular function after the placement of coronary-artery stents in acute myocardial infarction. coronary-artery stents in acute
Circulation 1998;98:2695-701.

23 Van den Merkhof LF, Zijlstra F, Olsson $\mathrm{H}$, et al. Abciximab in the treatment of acute myocardial infarction eligible for primary percutaneous transluminal coronary angioplasty. Results of the glycoprotein receptor antagonist patency evaluation (GRAPE) pilot study. I Am Coll Cardiol 1999;33:1528-32.

24 Makkar R, Golf B, Eigler N, et al. Effect of glycoprotein IIb/ IIIa inhibition without thrombolytic therapy on reperfusion in acute myocardial infarction: results of ReoMI pilot study. Catheter Cardiovasc Intervent 1999;48:430-4. 